\title{
Meledina (ou a história duma prostituta), de Aldino Muianga: a arte da memória
}

\author{
FRANCISCO NOA \\ Universidade Eduardo Mondlane
}

uma obra publicada, muito recentemente, no Brasil, intitulada $A$ arte de esquecer: cérebro, memória e esquecimento (2004), o médico e neurocientista Iván Izquierdo explica-nos, entre outras coisas, que "esquecemos para poder pensar, e esquecemos para não ficar loucos; esquecemos para poder conviver e para poder sobreviver" (p. 22). Ainda segundo ele, existem quatro formas de esquecimento: a extinção e a repressão, por um lado, que consistem em tornar as memórias menos acessíveis, mas sem perdê-las completamente; e o bloqueio e a deterioração, por outro lado, que representam perdas reais de informação, isto é, o esquecimento propriamente dito.

Se o bloqueio e a deterioração da memória são processos realmente penosos e deprimentes, a extinção e a repressão, aliadas a uma estratégia voluntária que é a falsificação, funcionam como formas, às vezes extremamente sofisticadas, da arte de esquecer e que serão responsáveis por construções, procedimentos e posturas reconhecíveis em momentos e lugares determinados.

Se a arte de esquecer, ainda na esteira de Iván Izquierdo, participa intensamente da nossa conformação psíquica e comportamental, seguramente a arte de lembrar, ou melhor, a de reinventar o passado, concorre decisivamente para definir aquilo que somos ou aquilo que pretendemos ser. É nesse sentido que, para Gabriel García Márquez, a vida não é a que a gente viveu, mas a que a gente lembra, e como lembra dela pode contá-la.

Como se pode observar por meio desse preâmbulo, é exactamente para a questão da memória que essa última obra de Aldino Muianga, afinal tal como as anteriores, nos remete. Memória do que aconteceu, mas sobretudo memória do que podia ter acontecido. Inscrevendo-se na melhor tradição aristotélica na perspectiva de que a literatura é mais filosófica do que a His- 
tória, a escrita de Aldino Muianga é uma interpelação às nossas consciências, individuais e colectivas, na sua relação com o tempo: com o passado, com o presente, mas acima de tudo com o futuro. Isto é, de onde viemos, o que somos, para onde e como vamos. Estamos, por conseguinte, perante um intenso e persistente apelo existencialista.

Pela forma como esse romance está construído, pela trama e pelos conflitos que o atravessam, podemos aí identificar algumas funções que a memória parece cumprir de forma particular. Primeiro, encontramos uma função ordenadora. Suzanne Langer, em Sentimento e forma, considera que toda arte é abstracção da existência material, de tal modo que o que a obra literária nos concede é uma ideia da própria vida, que é invariavelmente caótica, dispersa e fragmentária. E tal como a obra literária, a memória acaba por ser o grande ordenador da nossa existência, real ou virtual, de tal modo que todas as experiências, à medida que vão desfilando, assumem forma e carácter determinados. É pois essa função ordenadora instituída no romance Meledina que nos faz identificar um tempo, o tempo colonial, e um espaço físico e sócio-cultural dominante: o subúrbio que, por sua vez, interage activamente com outros dois espaços nucleares: o campo e a cidade. A história da prostituta Meledina é um pouco a nossa história colectiva, pois o percurso da personagem é uma errância constante entre o campo (a origem), a cidade (transição) e o subúrbio (o destino).

Em segundo lugar, podemos destacar, nessa última obra de Aldino, uma função pedagógica. O entendimento do mundo africano, na lúcida explicação de Wole Soyinka (2000, p. ix), só é possível se tivermos em conta a sua imensa complexidade e sobretudo as suas transformações devedoras, em muito, quer do fenómeno colonial, quer das dinâmicas contemporâneas que vão reconfigurando os traços originais desse mesmo universo.

Surgindo não necessariamente como visão nostálgica ou passadista, a recriação do passado em Meledina parece atracar-se a uma preocupação de projectar referências que se materializam numa instigante constelação de saberes. Assim, temos um saber histórico (o racismo colonial, as perseguições, a PSP, a Brigada Montada, a Polícia de Choque, a caderneta indígena, o cassetete, etc), um saber cultural (ligado à representação da oralidade, das tradições e dos mitos africanos), um saber sociológico (visível na figuração das dinâmicas e dos conflitos entre os diferentes grupos sociais), um saber linguístico (vejase a imitação das falas dos colonos na página 74), etc. 
Este cruzamento de saberes, múltiplos e variados, institui-se, de certo modo, como marca intrínseca do próprio imaginário africano que a literatura se vai encarregando de cristalizar. É o que constata a costamarfinense Tanella Boni, para quem a palavra depositou na nossa memória colectiva saberes que resultam de todas as provações experimentadas pelos africanos, como o tráfico de escravos, a colonização e todos os encontros felizes e infelizes com o outro (2001, p. 11). Ainda no entender dessa autora, passado muito tempo, essa memória é atravessada pela busca do nosso lugar no mundo.

Carregadas de um profundo simbolismo, as referências acima indicadas traduzem um apelo identitário que implicará sempre uma viagem essencial para dentro de nós próprios, em que através da superfície borbulhante e difusa das nossas memórias, colectivas e privadas, vemos reflectida a nossa verdadeira condição de seres em crise - existencial e ideológica. Contribui também intensamente para esta percepção o diálogo e o conflito entre os espaços: por um lado, entre o campo e o subúrbio e, por outro, entre o subúrbio e a cidade. Territórios sócio-culturais com uma enorme carga simbólica, as interacções que eles estabelecem representam, sobretudo, as "virtudes de complementaridade" que, no dizer de Soyinka, caracterizam todas as sociedades. Não ter isso em conta é condenar as sociedades africanas, por exemplo, à eterna condição de subalternidade e contingência.

Em terceiro lugar, reconhece-se, no romance de Aldino, a função morigeradora da memória, isto é, aquela que tem exactamente a ver com a reavaliação dos nossos costumes, claramente postos em evidência pelo autor implícito através da voz do narrador ou das personagens. Repare-se, por exemplo, quando a propósito de dar o nome à filha de Meledina, esta responde à proposta avançada pela irmã:

- Estás maluca ou quê? - admira-se Meledina, a soerguer-se da cama, o sobrolho carregado. - Será que não sabes que só os nossos pais é que têm o direito de dar um nome a esta minha primeira criança? São coisas dos nossos usos e costumes... (MUIANGA, 2004: 84)

A percepção e interiorização desses costumes parecem jogar um papel decisivo no processamento da memória como espaço de salvação na obra de Aldino Muianga. Seja ela memória autoconsciente, seja ela memória do mun- 
do para o qual é orientada. Isto é, apesar da relação que Meledina mantém intensamente com o colono Peixoto, fica claro que nenhum deles abdica dos valores culturais e morais do seu mundo original. Este é um aspecto central para apreender os sentidos profundos desse romance.

Projectando os desencontros vividos pelas personagens centrais do romance para o mundo em que hoje vivemos, "era do vazio", de todas as oscilações, de todas as incomunicações e de todas as fragilidades, e analisando os comportamentos esquizofrénicos que dominam a existência contemporânea, moral e culturalmente, o nível da nossa actual degradação parece infinitamente superior ao da prostituta Meledina.

Em quarto lugar, a memória funciona, em certa medida, como uma enorme mistificação. Aí fazem eco particular as inquietações do prefaciador da obra, Albino Magaia, que, entre outras coisas, questiona:

Estamos diante de um julgamento da sociedade colonial ou diante da sua apologia? Estamos diante da justificação e regeneração da prostituição ou diante da santificação da Mulher? Estamos aonde? [...] Estamos perante um livro que procura limpar a face dos colonos, dividindo-os entre bons e maus?

Estas e outras preocupações afins são, naturalmente, legítimas para quem lê o romance. Mais legítimas ainda para quem viveu e sofreu a situação colonial. Uma das linhas de força dessa obra é que ela persegue de modo quase obsessivo a sua vinculação à História. Desde os pretextos (Agradecimentos, Dedicatórias, Prefácio, a Nota de Apresentação, a Advertência do Autor), passando pelas múltiplas referências textuais, Meledina é mais uma singular expressão da tentativa de casar a ficção e a História, por sinal uma das maiores vocações do género romanesco.

Devido à preocupação do autor/narrador em humanizar tanto a negra Meledina como o branco Peixoto, o romance parece resvalar para uma "justificação" da prostituição ou da "regeneração" de alguns colonizadores. Nada mais falso. O próprio romance se encarrega de criar correctores que concorrem quer para a punição da prostituta (o ter sido desalojada da casa deixada pelo amante branco, a relação incestuosa da filha, a trombose que a acomete no final), quer para a condenação do colono (o abandono total a que veta a sua companheira negra e a filha e o seu fim inglório, em Portugal). Não existe 
nem boa colonização, nem bons colonizadores. Todas as formas de dominação, antigas ou modernas, comportam elementos insustentáveis de crueldade e desumanidade.

Apesar de o romance gravitar à volta dessas duas personagens, dificilmente elas podem emergir como heróis. Ambas são apenas protagonistas de uma história que não é uma história de amor, mas da sua impossibilidade, devido a condicionalismos vários inerentes às próprias personagens e ao contexto em que se encontram. Essa é, no fundo, uma história paradigmática da natureza dos cruzamentos raciais na sociedade colonial e, por outro lado, uma ilustração da génese problemática dos seres miscigenados.

Meledina (ou a história duma prostituta) não é necessariamente um romance moralista ou imoral. Trata-se simplesmente de uma vigorosa conjugação da energia criativa da escrita e da memória ao serviço tanto da própria literatura como das nossas consciências, mostrando-nos que os destinos, privados e colectivos, se tecem, afinal, na inesgotável e edificante arte de não esquecer.

\section{Referências Bibliográficas}

BONI, Tanella. Vivre, apprendre, comprendre. Notre Librairie, n. 144, p. 6-11, AvrilJuin 2001.

IZQUIERDO, Iván. $A$ arte de esquecer: cérebro, memória e esquecimento. Rio de Janeiro: Vieira \& Cent, 2004.

LANGER, Suzanne. Sentimento e forma. São Paulo: Perspectiva, 2001.

MUIANGA, Aldino. Meledina (ou a bistória duma prostituta). Maputo: Ndjira, 2004.

SOYINKA, Wole. Myth, literature and African world. Cambridge: University Press, 2000. 